\title{
Using Minority Stress Theory as a Conceptual Lens to Frame the Experiences of Teachers Who Identify as LGBTQ+
}

\author{
Stones Samuel and Glazzard Jonathan \\ Leeds Beckett University \\ Leeds, UK
}

\begin{abstract}
Throughout history teachers who identify as Lesbian, Gay, Bisexual, Transgender or Queer (LGBTQ+) have experienced prejudice, discrimination and restrictions to their agency. Heteronormative cultures have prevailed in schools worldwide, despite advances in legislation and the existence of more liberal attitude towards nonnormative gender identities and sexual orientations in recent years. This has resulted in teachers passing off as heterosexual or covering up their personal identities, resulting in internalised homophobia. This paper draws on Meyer's model of minority stress (Meyer, 2003) to illustrate how minority groups can be affected by overlapping stressors. It examines the limitations of this framework and presents an adapted version which more accurately reflects the factors which shape the experiences of teachers who identify as LGBTQ+.
\end{abstract}

Keywords: LGBTQ+; Teachers; Inclusion; Minority Stress; Schools.

\section{Introduction}

Despite an emphasis on whole school approaches to inclusion (Dimitrellou et al. 2018), evidence continues to suggest that some schools silence and marginalise non-heterosexual identities (DePalma \& Atkinson, 2009; Gray, 2013). Research involving the experiences of LGBTQ+ teachers is sparse (Gray et al. 2016) and many teachers who identify as LGBTQ+ continue to face discrimination in schools (Lineback et al. 2016) in England and internationally. Few students have been taught by a teacher openly identifying as LGBTQ+ (Lundin, 2015) and teachers with non-heterosexual identities continue to experience complications and constraints (Neary, 2017). Recent research demonstrates that forty percent of teachers identifying as LGBTQ+ do not feel included and the same proportion have experienced harassment, discrimination or prejudice because of their identification (Glazzard, 2018). Research by Glazzard (2018) also demonstrates that thirty percent of these teachers have reported that their experiences had a negative impact on their mental health. 
This article frames the experiences of LGBTQ+ teachers within Meyer's model of minority stress (Meyer, 2003). It presents Meyer's original model and then offers an adapted model to illustrate the factors which directly influence stress, agency and resilience for teachers who identify as LGBTQ+.

\section{International context}

This section considers the international research on the experiences of teachers with LGBTQ+ identities. Regardless of the legal status of homosexuality, religion and culture shape public opinion on its acceptability (Adamczyk \& Pitt, 2009). Research demonstrates that teachers with LGBTQ+ identities from across the world continue to experience discrimination and marginalisation (King et al. 2008; Hardie, 2012; Marris \& Staton, 2016) and various factors restrict the willingness and ability of teachers to declare their sexuality in schools and colleges (Wright \& Smith, 2015).

Neary (2013) has argued that the "battles" (p. 583) of the LGBTQ+ community have progressed a worldwide movement through reshaping perceptions of family, marriage and work. Historically heterosexuality has been embedded in the practices of institutions and the encounters of our everyday life (Epstein \& Johnson, 1994). Although the rights of individuals with LGBTQ+ identities have been strengthened across Europe over recent decades (Lundin, 2015), international research continues to demonstrate that heteronormative and heterosexist cultures are entrenched within schools in Asian and African countries (Kjaran \& Kristinsdóttir, 2015). There is also evidence that these normative values are inculcated within schools in countries where homosexuality is legal, including Australia (Gray et al. 2016) and the United States (Lineback et al. 2016).

\section{The context in England}

Homosexuality was partially decriminalised in England and Wales in 1967. Prior to this, individuals engaging in homosexual acts faced a maximum sentence of life in prison. Despite being decriminalised, official and legal disapproval of homosexuality continued for many years with inequality remaining prevalent (Epstein, 2000; Nixon \& Givens, 2007). Introduced by Margaret Thatcher's Conservative government in 1988, Section 28 (Local Government Act, 1988) signalled this disapproval by seeking to impose upon local authorities and their schools a prescribed view which sought to restrict public acceptance of sexuality (Nixon \& Givens, 2007). It has been argued that:

"Section 28 (part of the Local Government Act of 1988) was a notorious piece of legislation that sought to prevent local education authorities in the UK from 'promoting homosexuality'. The effect of Section 28 was to create uncertainty and fear among teachers as to what was (and what was not) permitted in schools."

(Greenland \& Nunney, 2008, p. 243) 
Recent research demonstrates the powerful and long-lasting cultural effect of Section 28 (Edwards et al. 2016). It contributed to a climate of fear through the normalisation of heterosexuality, thus resulting in marginalisation, oppression and regulation of those with deviant sexual identities (Neary, 2013). It has been emphasised that:

\begin{abstract}
"Most research referring to [Section 28] has been highly critical, viewing it as symbolic discrimination that institutionalizes a hierarchical relationship between heterosexuality and homosexuality, and it is held up as a prime example of the exclusion of lesbians and gay men from full cultural citizenship."
\end{abstract}

(Burridge, 2004, p. 329)

Teachers held several misconceptions about Section 28, especially in relation to what was legal and what was not, and this uncertainty led to confusion (Warwick et al. 2001). For example, teachers were often unable to draw distinctions between promoting homosexuality and simply providing students with advice (Greenland \& Nunney, 2008). In addition, many teachers were unsure about the legality of discussing homosexuality, and this often led to an avoidance of the subject entirely (Buston \& Hart, 2001). This meant that schools avoided discussion of LGBTQ+ topics and any related curricula (Epstein et al. 2003). Research also demonstrates that Section 28 supported the growth of homophobic bullying through creating school cultures which failed to challenge and address homophobic bullying and harassment (Epstein, 2000; Warwick et al. 2001).

Section 28 prohibited schools from promoting homosexuality or its acceptability as a "pretended family relationship" (Local Government Act, 1988). This normalised heterosexual marriage (Nixon \& Givens, 2007) and sustained cultures of heteronormativity in schools, despite the partial decriminalisation of homosexuality over twenty years earlier. Thus, Section 28 reinforced the marginalisation of those with non-conforming identities. As demonstrated by Foucault (1978) and Ellis (2007), sexuality has been historically associated with disease and mental illness. Through condemning difference, Section 28 effectively positioned teachers with non-heterosexual identities as patients and sufferers (Ellis, 2007) whose divergence and difference left them feeling at risk and in need of help (Quinlivan, 2002).

Section 28 was repealed in England and Wales in 2003. However, despite this, research demonstrates that the legislation continued to impact and influence teachers' practice for many years after its repeal (Greenland \& Nunney, 2008; Edwards et al. 2016). Researchers have also argued that this repeal was a superficial change in legislation which only went a small way in challenging the deep heterosexist discourse and gross inequality already embedded in schools (Nixon \& Givens, 2007).

Despite the negative historical context in England, the 2010 White Paper, The Importance of Teaching: The Schools' White Paper was essentially a catalyst for 
change. This document marked the government's commitment to eradicating homophobia, biphobia and transphobia in Britain's schools. In recent years, policy texts in England have highlighted the role of schools in addressing homophobic, biphobic and transphobic bullying. This has been a political priority (DfE, 2010; GEO, 2018). The Equality Act (2010) places a legal duty on all employers, including schools, and therefore their leaders and governors, to protect students and employees with 'protected characteristics' from any direct or indirect forms of discrimination. These protected characteristics include, amongst others, sexual orientation and gender reassignment. Further strengthening this protection, the Equality Act (2010) also requires schools to support and foster positive relations between individuals with a shared protected characteristic and those without.

Schools and initial teacher training providers are accountable for promoting equality and fostering an understanding of, and respect for, those with protected characteristics (Ofsted, 2018a; Ofsted, 2018b). In recent years, inspection frameworks in England have been revised to strengthen this accountability and ensure school staff and initial teacher training providers are addressing prejudice-based bullying within schools and during the training of new teachers. In addition to these frameworks, the government's Sex and Relationship Education Guidance (DfEE, 2000) for schools has been recently updated to highlight the importance of inclusive and age-appropriate relationships and sex education through addressing LGBTQ+ relationships and same-sex marriage (Brook et al. 2018). However, the new statutory guidance is a subject of much debate and some religious groups have challenged it publicly. The new guidance provides schools with flexibility in deciding how to address LGBTQ+ relationships. It is possible that this will result in the inconsistent application and interpretation of the guidance, particularly within schools where discriminatory or prejudicial views are held by leaders, governors and parents.

In England, the government's attempts to tackle prejudice-based bullying are progressive, although with the exception of the Equality Act (2010), emphasis within government documentation has mainly focussed on protecting students with LGBTQ+ identities rather than school staff. Although this legislation may have encouraged more teachers to openly declare their sexuality (DePalma \& Jennett, 2010), little is known about the impact of the Equality Act (2010) as research is limited. However, regardless of its impact, research continues to demonstrate incidences of homophobic bullying and harassment of those with protected characteristics (Ferfolja \& Hopkins, 2013; Hardie, 2012; Marris \& Staton, 2016). In addition, research also demonstrates the many barriers facing teachers in openly declaring their LGBTQ+ identities. These include: abuse from students (DePalma \& Jennett, 2010); parental discomfort (Piper \& Sikes, 2010); discrimination from school leaders (Ferfolja \& Hopkins, 2013) and the clash between religion and sexuality in some faith and religious schools (Gray et al. 2016).

The revision of policies and legislation signal the government's commitment to LGBTQ+ inclusion (DePalma \& Jennett, 2010), but despite this research continues to evidence the scale of homophobic, biphobic and transphobic 
bullying in Britain's schools (Bradlow et al. 2017). Whilst the reasons for this are complex, multifaceted and often misunderstood (Formby, 2015), research by Bradlow et al. (2017) does illuminate the disconnection between the government's expectations and the lived experiences of those within the LGBTQ+ community.

It is therefore reasonable to argue that the government's attempts to tackle prejudice-based bullying in England have relied on reactive approaches which have failed to address the reasons that underpin the existence of prejudice. It appears that school leaders and governors need to place greater emphasis on the proactive promotion of LGBTQ+ inclusion. In doing so, schools and their staff can change and challenge people's thinking about sexuality and gender rather than simply regulating the actions and behaviours of those who discriminate.

\section{Literature}

A narrative literature review was carried out. Narrative literature reviews seek to locate literature under key themes and combine these to produce a thematic and holistic understanding of a specific field. As such, narrative literature reviews create a "map" (Hammersley, 2001, p. 548) of studies that highlights the many parts of a "single picture" (ibid).

Much research has demonstrated the harassment and discrimination of teachers with LGBTQ+ identities (Cooper, 2008; Neary, 2013; Glazzard, 2018). Dominant heteronormative discourses in schools often situate teachers with LGBTQ+ identities within exclusionary spaces (Gray et al. 2016). Research has linked these experiences of bullying, violence, invisibility and alienation with elevated risks of mental ill health, self-harm and suicidality (Mayock et al. 2009; Bryan \& Mayock, 2017). Eliason (2010) conceptualises the "suicide consensus" (p. 7) that has emerged from over 30 years of research which illustrates the heightened risk of suicide for those who identify as LGBTQ+ compared to those with normative gender identities and sexual orientations (Bryan \& Mayock, 2017).

Teachers who identify as LGBTQ+ are required to negotiate complex personal and professional boundaries (Vicars, 2006; Gray, 2013) and decide whether or not to be visible and open about their personal identities (Grace \& Benson, 2000). This isolation has deterred teachers from assuming positions as visible role models in schools (Russell, 2010; Gray et al. 2016). To conceal and reduce stigmatising attributes, individuals with LGBTQ+ identities will often pass off and cover up (Goffman, 1963) their identities in order to seek acceptance and equivalence. Through doing so, these teachers conform to the heteronormative and heterosexist discourses that prevail in schools (Gray et al. 2016; Reimers, 2017), conceal their identities and experience internalised homophobia.

According to Røthing (2008), teachers' experiences are influenced by "homotolerant" (p. 258) school cultures. Although heteronormativity might be less overt than it was previously (Berry, 2018), it still exists in subtle forms (Gray et al. 2016) including through bias and microaggressions (Francis \& Reygan, 2016). Despite microaggressions originally emerging from race-based research 
(Lynn, 2002; Yosso 2005), they have been explored in recent years in relation to sexual orientation and gender identity (Nadal et al. 2011; Francis \& Reygan, 2016). Microaggressions therefore appear in a range of settings and contexts and can be understood as:

“...brief and commonplace daily verbal, behavioural, or environmental indignities, whether intentional or unintentional, that communicate hostile, derogatory, or negative slights and insults towards members of oppressed groups."

(Nadal, 2008, p. 23)

Research has demonstrated that the LGBTQ+ community, including staff and students in schools, is exposed to microaggressions and subtle bias which perpetuate heterosexism and exclude those with LGBTQ+ identities (Walls, 2008; Nadal et al. 2011). Francis and Reygan's (2016) research has summarised the microaggressions facing those in the LGBTQ+ community. These include: heterosexist language; heteronormative and gender normative discourses; exoticising the identities of LGBTQ+ individuals; outright disapproval of those with LGBTQ+ identities; denying homophobia and pathologising those within the LGBTQ+ community (Francis \& Reygan, 2016). Minikel-Lacoque's (2013) research also characterises the contested microaggressions which occur when aggressors deliberately and purposefully deny their actions.

Research demonstrates many of the factors contributing to the oppression of teachers with LGBTQ+ identities (Vicars, 2006; DePalma \& Jennett, 2010; Piper \& Sikes, 2010; Ferfolja \& Hopkins, 2013; Gray, 2013; Gray et al. 2016). In addition to this research, teachers with LGBTQ+ identities have also been viewed with suspicion by parents and other adults (Rudoe, 2010). Also, discourses of safeguarding which position children as vulnerable and in need of protection have meant that a teacher's disclosure of their sexuality might be considered inappropriate (Gray et al. 2016). In addition, teachers within the LGBTQ+ community have also been accused of seeking to promote a "gay agenda" through attempts to recruit children to the field of homosexuality (Rudoe, 2010).

Although there is a paucity of literature available (Ferfolja \& Hopkins, 2013), research does demonstrate that the experiences of LGBTQ+ students have improved in very recent years with more students now self-identifying as LGBTQ+ to resist bigotry and discrimination (Berry, 2018). Despite this, research demonstrating the positive accounts of teachers in England remains sparse.

\section{Conceptual framework}

This discussion focuses on Meyer's (2003) conceptual framework which demonstrates how minorities experience additional stressors in addition to the general stressors that are experienced by everyone. The model is particularly useful in helping to frame the experiences of teachers who identify as LGBTQ+ because the existing literature positions them as victims of heteronormative school cultures. For teachers with non-normative gender identities and sexual orientations, working within heteronormative and "homotolerant" (Røthing, 
2008) environments is likely to produce additional stressors which layer on top of the usual stressors that are associated with life in general and teaching.

Meyer's (2003) theory includes three elements: circumstances in the environment (general stressors); negative experiences as a result of belonging to a minority identity (distal stressors) and the anticipation or expectation of negative experiences due to previous experience of prejudice, discrimination and harassment (proximal stressors). Meyer's (2003) model is shown in Figure 1 below:

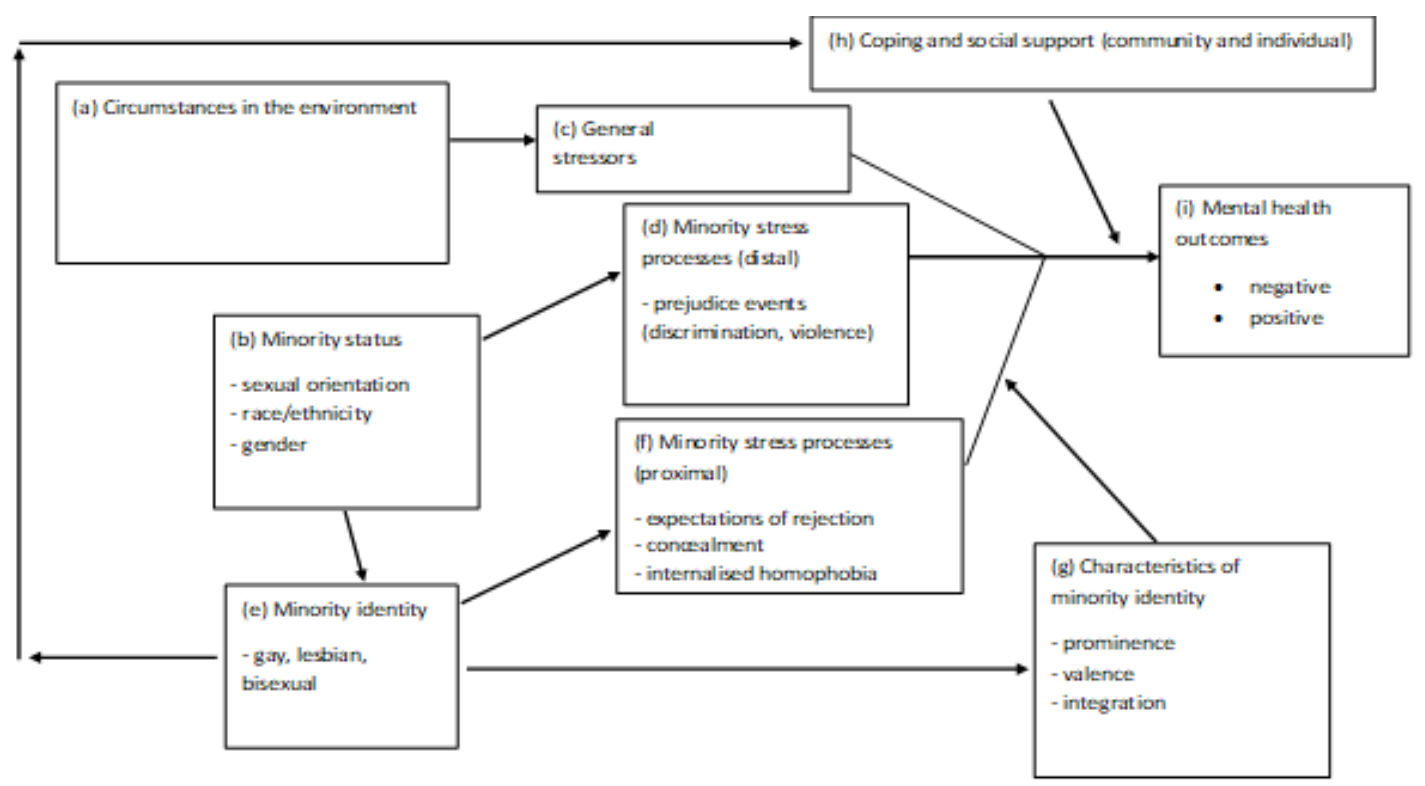

Figure 1: Meyer's Minority Stress Theory (2003)

According to Meyer (2003), the minority stress theory positions general stressors within the wider environment. These environmental circumstances include poverty, redundancy and bereavement and each will produce general stressors. In contrast, minority stressors relate to a person's identity and their association with a minority group (Meyer, 2003), such as the LGBTQ+ community. Thus, a minority identity, including being gay, lesbian or transgender, will produce minority stressors which intersect with general stressors.

Holman (2018) conceptualises distal stressors as those which are external to an individual. They include the experience of rejection, discrimination, prejudice and stigma based on sexual orientation or gender identity. These experiences may be reinforced or shaped by structural forces including racism and heteronormativity.

Proximal stressors relate to an individual's perception and appraisal of a situation. An individual with a minority identity may expect or anticipate rejection, prejudice and discrimination based on previous negative experiences (distal stressors) of these. These expectations and anticipations are internal to an individual. Individuals may employ self-vigilance and concealment to reduce the likelihood of these negative experiences occurring (Miller \& Major, 2000; Velez et al. 2013), resulting in internalised homophobia. 
Meyer's (2003) model suggests that opportunities for minority groups to develop affiliation and social support with others who share the minority status can "ameliorate" (Meyer, 2003, p. 9) the impact of stress. Developing this argument further, it might be argued that in some cases, a minority identity can actually become a "source of strength" (ibid) if the identity itself is used as a vehicle to pursue opportunities for affiliation.

\section{Critique of the model}

Although the model offers a useful conceptual tool for framing the experiences of teachers who identify as LGBTQ+, it situates them within a victimised framework. In addition, it only offers a limited range of coping strategies which can potentially change negative mental outcomes into positive mental health outcomes. We offer a critique of the model below and then present an adapted model to better reflect lived experiences of this group of teachers.

Minority stress theory pathologises minority groups by locating individuals within a victimised framework (Lytle, 2014). As a result, the theory accepts the existence of prejudice and offers no solutions for eradicating this (Meyer, 2003) other than forming social networks to counteract the experiences of prejudice and discrimination. As a conceptual framework it neglects the role of wider structural and institutional forces in allowing prejudice and discrimination to shape the experiences of individuals with minority status.

Alternative perspectives in psychology offer greater hope and challenge the tragic narrative which is dominant in the LGBTQ+ literature. For example, research in positive psychology reminds us of the strengths which exist within the LGBTQ+ community (Bandura, 2001; Lytle, 2014) and minority stress theory fails to recognise that the experiences of those within minorities may improve as a result of these strengths (Lytle, 2014). Psychology literature often sees heterosexual groups as the norm and therefore frames LGBTQ+ experiences through a pathological or deficit lens (ibid) which overlooks the agentic strengths of those with LGBTQ+ identities (Bandura, 2001; Lytle, 2014). Meyer's model reflects this deficit perspective. There is a need for theories which interrogate and deconstruct prejudices and recognise the potential for lives and experiences to be improved and changed for the better.

Traditionally, psychology has focused on the toxic circumstances that induce stress and the minority stress theory captures these (Toussaint et al. 2016). In contrast, the theory of innate health emphasises the power held by an individual in determining how stress will affect them (Pransky \& Kelley, 2014). This theory argues that people have a reserve of innate well-being which can be drawn upon to address stress (Sedgeman, 2005). Thus, by focusing their mind, thoughts and consciousness on positive aspects, external general and distal stressors do not have to result in internalised psychological distress. Whilst minority stress theory disempowers and victimises minority groups (Meyer, 2003), the theory of innate health ascribes minority groups with agency and empowerment (Pransky \& Kelley, 2014). 


\section{Adapting the model}

Whilst Meyer's original model (Meyer, 2003) identified the importance of social support mechanisms in producing positive mental health outcomes for minority groups, it restricts these to social support from other individuals with the same minority status and community support. We offer an adapted model in Figure 2 which more accurately reflects the experiences of teachers who identify as LGBTQ+.

In Figure 2 the elements of Meyer's (2003) original model are maintained: environmental circumstances result in general stressors and an individual's minority status can result in both distal and proximal stressors. However, our adapted model includes a broader range of factors (h-p in Figure 2) which can result in both positive and negative mental health outcomes. In this discussion we focus specifically on the impact of legislation on teacher identity, efficacy, agency and resilience.

The Equality Act (2010) makes it unlawful to discriminate against individuals on the basis of sexual orientation and gender reassignment. These are characteristics which protect LGBTQ+ teachers and students from discrimination in schools. Following the introduction of the Equality Act (2010), revisions to school inspection frameworks in England included greater emphasis on LGBTQ+ inclusion which resulted in inspectors giving greater attention to aspects such as homophobic, biphobic and transphobic bullying in determining school inspection judgements. The legislation provides reassurance to teachers who identify as LGBTQ+ who do not wish to separate their personal and professional identities. Thus, if a teacher wishes to disclose their sexual orientation or gender identity in school, the Equality Act (2010) provides them with protection from possible discrimination. These changes to legislation and regulatory frameworks can have a positive impact on teacher efficacy and agency because they provide teachers with permission to express their personal identities in schools and the confidence to implement a whole-school approach to LGBTQ+ inclusion without fear of experiencing discrimination. Teachers who are resilient to negative 'backlash' from parents, students or colleagues are more likely to experience positive mental health outcomes. However, resilience is not solely innate to individuals. It is influenced by support from family, friends and professional networks, legislative and regulatory frameworks, school culture and by an individual's status (power) within the school. Negative school cultures which restrict agency and identity can result in some teachers with nonnormative gender identities and sexual orientations seeking employment in schools which provide them with identity affirming cultures (geographic displacement). We therefore propose that these factors should be central to adaptations of Meyer's model when it is applied to the experiences of teachers who identify as LGBTQ+. 


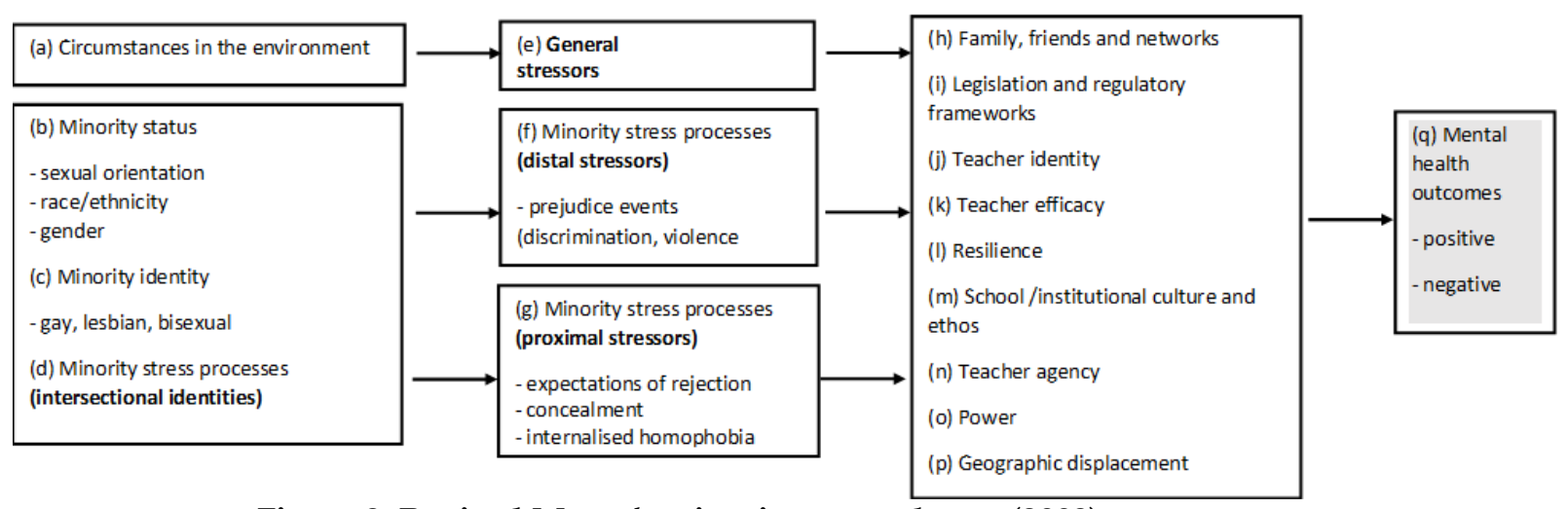

Figure 2: Revised Meyer's minority stress theory (2003)

\section{Conclusion and Recommendations}

In this paper we have presented an adapted version of Meyer's minority stress theory to illustrate the factors which can result in positive and negative mental health outcomes for teachers who identify as LGBTQ+. We have focused on the role of legislative and regulatory frameworks in developing teacher identity, efficacy, agency and resilience for teachers who identify as LGBTQ+. Although existing literature emphasises the negative effects of heteronormative school cultures on the teacher agency, identities and resilience, this only offers a partial understanding of the experiences of teachers with non-normative gender identities and sexual orientations. Legislation and regulatory frameworks which shape educational policies and practices in England can potentially increase teacher agency and the willingness of LGBTQ+ teachers to merge their personal and professional identities. However, we acknowledge that some teachers may not wish to disclose their personal identities within their professional contexts. At the same time, we recognise that teachers' lived experiences are not only influenced by these wider discourses and that factors relating to the school context will also influence their agency, identity and resilience. For example, the lived experiences of teachers who identity as LGBTQ+ may be shaped by the attitudes of school leaders, school culture, the catchment area and religious affiliations.

Further research is required to test out this adapted framework in relation to the lived experiences of teachers who identify as LGBTQ+ and subsequent research should seek to move the debate beyond the tragic narratives of LGBTQ+ lives which are dominant within existing literature. These accounts only partially illuminate the experiences of teachers who identify as LGBTQ+ and these accounts situate LGBTQ+ teachers as victims rather than as agents of change within schools. Thus, we argue that future research should position LGBTQ+ teachers as agentic individuals who are able to advance an agenda of social justice. 


\section{References}

Adamczyk, A., and Pitt, C., (2009), 'Shaping attitudes about homosexuality: The role of religion and cultural context' in, Social Science Research, Volume 38, Number 2, June 2009, pp. 338-351. https://doi.org/10.1016/j.ssresearch.2009.01.002

Bandura, A. (2001), 'Social Cognitive Theory: An Agentic Perspective' in, Annual Review of Psychology, Volume 52, Number 1, February 2001, pp. 1-26. https://doi.org/10.1111/1467-839x.00024

Berry, K. (2018), 'Wicked problems forum: freedom of speech at colleges and universities' in, Communication Education, Volume 67, Number 4, February 2018, pp. 502-531.

Bradlow, J., Bartram, F., Guasp, A., \& Jadva, V. (2017), 'School Report' [Online], Available https://www.stonewall.org.uk/sites/default/files/the_school_report_2017.pdf, Accessed November 28th 2018.

Brook, S., Emmerson, L., Hayman, J., \& Lees, J. (2018), 'Sex and Relationships Education (SRE) for the 21st Century' [Online], Available at https://www.psheassociation.org.uk/system/files/SRE\%20for\%20the\%2021st\%20Century\%20\%20FINAL.pdf.pdf, Accessed December 26th 2018.

Bryan, A., \& Mayock, P. (2017), 'Supporting LGBT Lives? Complicating the suicide consensus in LGBT mental health research' in, Sexualities, Volume 20, Number 1, February 2017, pp. 65-85. https:// doi.org/10.1177/1363460716648099

Buston, K., and Hart, G., (2001), 'Heterosexism and homophobia in Scottish school sex education: Exploring the nature of the problem' in, Journal of Adolescence, Volume 24, Number 1, February 2001, pp. 95-109. https://doi.org/10.1006/jado.2000.0366

Burridge, J. (2004), 'I am not homophobic but...: Disclaiming in discourse resisting repeal of section 28' in, Sexualities, Volume 7, Number 1, August 2004, pp. 327344. https://doi.org/10.1177/1363460704044804

Cooper, L. (2008), 'On the other side: Supporting sexual minority students' in, British Journal of Guidance and Counselling, Volume 36, Number 4, October 2008, pp. 425-440. https:// doi.org/10.1080/03069880802364577

DePalma, R., \& Atkinson, E. (2009), 'No Outsiders: moving beyond a discourse of tolerance to challenge heteronormativity in primary schools' in, British Educational Research Journal, Volume 35, Number 6, December 2009, pp. 837855. https://doi.org/10.1080/01411920802688705

DePalma, R., \& Jennett, M. (2010), 'Homophobia, transphobia and culture: deconstructing heteronormativity in English primary schools' in, Intercultural Education, Volume 21, Number 1, April 2010, pp. 15-26. https:// doi.org/10.1080/14675980903491858

Department for Education (DfE), (2010), 'The Importance of Teaching: The Schools' White Paper 2010' [Online], Available at https://assets.publishing.service.gov.uk/government/uploads/system/upload s/attachment_data/file/175429/CM-7980.pdf, Accessed December 26th 2018.

Department for Education and Employment (DfEE), (2000), 'Sex and Relationship Education Guidance' [Online], Available at https:// https://webarchive.nationalarchives.gov.uk/20130403224457/https:/www.edu cation.gov.uk/publications/eOrderingDownload/DfES-0116-2000\%20SRE.pdf, Accessed December 26th 2018.

Diaz, R.M., Ayala, G., Bein, E., Jenne, J., \& Marin, B.V. (2001), 'The impact of homophobia, poverty, and racism on the mental health of gay and bisexual 
Latino gay men' in, American Journal of Public Health, Volume 91, Number 1, June 2001, pp. 927-932. https://doi.org/10.2105/ajph.91.6.927

Dimitrellou, E., Hurry, J., and Male, D., (2018), 'Assessing the inclusivity of three mainstream secondary schools in England: challenges and dilemmas' in, International Journal of Inclusive Education, August 2018, pp. 1-17. https://doi.org/10.1080/13603116.2018.1511757

Edwards, L., Brown, D., and Smith, L., (2016), 'We are getting there slowly: lesbian teacher experiences in the post-Section 28 environment' in, Sport, Education and Society, Volume 21, Number 3, August 2014, pp. 299-318. https:// doi.org/10.1080/13573322.2014.935317

Eliason, M. (2010), 'Introduction to Special Issue on suicide, Mental Health, and Youth Development' in, Journal of Homosexuality, Volume 58, Number 1, January 2011, pp. 4-9. https:// doi.org/10.1080/00918369.2011.533622

Ellis, V. (2007), 'Sexualities and Schooling in England After Section 28: Measuring and Managing "At-Risk" Identities' in, Journal of Gay and Lesbian Issues in Education, Volume 4, Number 3, July 2007, pp. 13-30. https://doi.org/10.1300/j367v04n03_03

Epstein, D., \& Johnson, R., (1994), On the straight and narrow: The heterosexual presumption, homophobias and schools, Buckingham: Open University Press.

Epstein, D., (2000), 'Sexualities and education: Catch 28' in, Sexualities, Volume 3, Number 4, November 2000, pp. 387-394. https://doi.org/10.1177/136346000003004001

Epstein, D., O'Flynn, S., \& Telford, D. (2003), Silenced sexualities in schools and Universities, Stoke on Trent: Trentham.

Equality Act, (2010), 'Protected characteristics' [Online], Available at https://www.legislation.gov.uk/ukpga/2010/15/pdfs/ukpga_20100015_en.pd f, Accessed December 25th 2018.

Ferfolja, T., \& Hopkins, L. (2013), 'The complexities of workplace experience for lesbian and gay teachers' in, Critical Studies in Education, Volume 54, Number 3, May 2013, pp. 311-324. https://doi.org/10.1080/17508487.2013.794743

Formby, E. (2015), 'Limitations of focussing on homophobic, biphobic and transphobic 'bullying' to understand and address LGBT young people's experiences within and beyond school' in, Sex Education, Volume 15, Number 6, July 2015, pp. 626640. https://doi.org/10.1080/14681811.2015.1054024

Foucault, M. (1978), The History of Sexuality, Paris: Gallimard.

Francis, D., \& Reygan, F. (2016), 'Let's see it if won't go away by itself: LGBT microaggressions among teachers in South Africa' in, Education as Change, Volume 20, Number 3, December 2016, pp. 180-201. https://doi.org/10.17159/1947-9417/2016/1124

Glazzard, J. (2018), 'Pride and prejudice: how LGBT teachers suffer in our schools' [Online], Available at https://www.tes.com/magazine/article/pride-andprejudice-how-lgbt-teachers-suffer-our-schools, Accessed April 16th 2019.

Goffman, E., (1963), Stigma: Notes on the management of spoiled identity, New York: Simon and Schuster.

Government Equalities Office (GEO), (2018), LGBT Action Plan: Improving the Lives of Lesbian, Gay, Bisexual and Transgender People, GEO.

Grace, A.B., \& Benson, F.J. (2000), 'Using autobiographical queer life narratives of teachers to connect personal, political and pedagogical spaces' in, International Journal of Inclusive Education, Volume 4, Number 2, November 2010, pp. 89109. https://doi.org/10.1080/136031100284830 
Gray, E. (2013), 'Coming out as a lesbian, gay or bisexual teacher: negotiating private and professional worlds' in, Sexuality, Society and Learning, Volume 13, $\begin{array}{llll}\text { Number 6, November 2013, p. } & \text { 702-714. }\end{array}$ https://doi.org/10.1080/14681811.2013.807789

Gray, E., Harris, A., \& Jones, T. (2016), 'Australian LGBTQ teachers, exclusionary spaces and points of interruption' in, Sexualities, Volume 19, Number 3, March 2016, pp. 286-303. https://doi.org/10.1177/1363460715583602

Greenland, K., \& Nunney, R. (2008), 'The repeal of Section 28: it ain't over 'til it's over' in, Pastoral Care in Education, Volume 26, Number 4, December 2008, pp. 243251. https://doi.org/10.1080/02643940802472171

Hammersley, M. (2001), 'On "systematic" reviews of research literatures: A "narrative" response to Evans and Benefield' in, British Educational Research Journal, Volume 27, Number 5, December 2001, pp. 543-554. https://doi.org/10.1080/01411920120095726

Hardie, A. (2012), 'Lesbian teachers and students: issues and dilemmas of being 'out' in primary school' in, Sex Education, Volume 12, Number 3, July 2012, pp. 273-282. https:// doi.org/10.1080/14681811.2011.615595

Holman, E. (2018), 'Theoretical Extensions of Minority Stress Theory for Sexual Minority Individuals in the Workplace: A Cross-Contextual Understanding of Minority Stress Processes' in, Journal of Family Theory and Review, Volume 10, Number 1, March 2018, pp. 165-180. https://doi.org/10.1111/jftr.12246

King, E.B., Reilly, C., \& Hebl, M. (2008), 'The best of times, the worst of times: Exploring dual perspectives of "coming out" in the workplace' in, Group and Organization Management, Volume 33, Number 5, October 2008, pp. 566-601. https:// doi.org/10.1177/1059601108321834

Kjaran, J., \& Kristinsdóttir, G. (2015), 'Schooling sexualities and gendered bodies. Experiences of LGBT students in Icelandic upper secondary schools' in, International Journal of Inclusive Education, Volume 19, Number 9, March 2015, pp. 978-993. https://doi.org/10.1080/13603116.2015.1019375

Lineback, S., Allender, M., Gaines, R., \& McCarthy, C. (2016), 'They think I am a pervert: A Qualitative Analysis of Lesbian and Gay Teachers' Experiences With Stress at School' in, A Journal of the American Educational Studies Association, Volume 52, Number 6, October 2016, pp. 592-613. https:// doi.org/10.1080/00131946.2016.1231681

Local Government Act, (1988), 'Prohibition on promoting homosexuality by teaching or by publishing material' [Online], Available at https://www.legislation.gov.uk/ukpga/1988/9/pdfs/ukpga_19880009_en.pdf, Accessed December 16th 2018.

Lundin, M. (2015), 'Homo- and bisexual teachers' ways of relating to the heteronorm' in, International Journal of Educational Research, Volume 75, December 2015, pp. 67-75. https://doi.org/10.1016/j.ijer.2015.11.005

Lynn, M. (2002), 'Critical race theory and the perspectives of black men teachers in the Los Angeles public schools' in, Equity and Excellence in Education, Volume 35, Number 2, December 2002, pp. 119-130. https:/ / doi.org/10.1080/713845287

Lytle, M., Vaughan, M., Rodriguez, E., \& Shmerler, D. (2014), 'Working with LGBT Individuals: Incorporating Positive Psychology into Training and Practice' in, Psychology of Sexual Orientation and Gender Diversity, Volume 1, Number 4, October 2014, pp. 335-347. https:// doi.org/10.1037/sgd0000064

Marris, S., \& Staton, R. (2016), 'Negotiating Difficult Decisions: coming Out versus Passing in the Workplace' in, Journal of LGBT Issues in Counseling, Volume 10, 
$\begin{array}{lllll}\text { Number } & 1, & \text { January } & \text { 2016, }\end{array}$ https:// doi.org/10.1080/15538605.2015.1138097

Mayock, P., Bryan, A., Carr, N., \& Kitching, K. (2009), 'Supporting LGBT Lives' [Online], Available at http://lgbt.ie/wpcontent/uploads/2018/06/attachment_233_Supporting_LGBT_Lives_Key_Find ings_Report_Card.pdf, Accessed November 27th 2018].

Meyer, I.H. (2003), 'Prejudice, Social Stress, and Mental Health in Lesbian, Gay and Bisexual Populations: Conceptual Issues and Research Evidence' in, Psychological Bulletin, Volume 129, Number 5, September 2003, pp. 674-697. https://doi.org/10.1037/0033-2909.129.5.674

Miller, C.T., \& Major, B. (2000), 'Coping with stigma and prejudice', in Heatherton, T.F., Kleck, R.E., Hebl, M.R., and Hull, J.G., (eds.), The social psychology of stigma, New York: Guilford Press, pp. 257-266.

Minikel-Lacocque, J. (2013), 'Racism, college, and the power of words: Racial microaggressions reconsidered' in, American Educational Research Journal, Volume 50, Number 3, June 2013, pp. 432-465. https://doi.org/10.3102/0002831212468048

Nadal, K.L. (2008), 'Preventing racial, ethnic, gender, sexual minority, disability, and religious Microaggressions' in, Prevention in Counseling Psychology: Theory, Research, Practice and Training, Volume 2, Number 2, January 2008, pp. 22-27.

Nadal, K.L., Issa, A.M., Leon, J., Meterko, V., Wideman, M., \& Wong, Y. (2011), 'Sexual Orientation Microaggressions: 'Death by a thousand cuts' for lesbian, gay, and bisexual youth' in, Journal of LGBT Youth, Volume 8, Number 3, July 2011, pp. 234-259. https:/ / doi.org/10.1080/19361653.2011.584204

Neary, A. (2013), 'Lesbian and gay teachers' experiences of 'coming out' in Irish schools' in, British Journal of Sociology of Education, Volume 34, Number 4, September 2012, pp. 583-602. https:// doi.org/10.1080/01425692.2012.722281

Neary, A., (2017), 'Lesbian, gay and bisexual teachers' ambivalent relations with parents and students while entering into a civil partnership' in, Irish Educational Studies, Volume 37, Number 1, March 2017, pp. 7-72. https:// doi.org/10.1080/03323315.2017.1289702

Nixon, D., \& Givens, N. (2007), 'An epitaph to Section 28? Telling tales out of school about changes and challenges to discourses of sexuality' in, International Journal of Qualitative Studies in Education, Volume 20, Number 4, May 2007, pp. 449471. https://doi.org/10.1080/09518390601176564

Ofsted, (2018a), 'School inspection handbook' [Online], Available at https://assets.publishing.service.gov.uk/government/uploads/system/upload s/attachment_data/file/730127/School_inspection_handbook_section_5_270718 .pdf, Accessed December 26th 2018.

Ofsted, (2018b), 'Initial teacher education inspection handbook' [Online], Available at https://assets.publishing.service.gov.uk/government/uploads/system/upload s/attachment_data/file/737106/ITE_handbook_September_2018_300818.pdf, Accessed December 26th 2018.

Piper, H., \& Sikes, P. (2010), 'All Teachers are Vulnerable but Especially Gay Teachers: Using Composite Fictions to Protect Research Participants in Pupil-Teacher SexRelated Research' in, Qualitative Inquiry, Volume 16, Number 7, August 2010, pp. 566-574. https://doi.org/10.1177/1077800410371923

Pransky, J., \& Kelley, T. (2014), 'Three Principles for Realizing Mental Health: A New Psychospiritual View' in, Journal of Creativity in Mental Health, Volume 9, Number 1, March 2014, pp. 53-68. https://doi.org/10.1080/15401383.2013.875864 
Quinlivan, K. (2002), 'Whose problem is this? Queerying the framing of lesbian and gay secondary school students within "at risk" discourses' in, Journal of Gay and Lesbian Social Services, Volume 14, Number 2, March 2002, pp. 17-31. https://doi.org/10.1300/j041v14n02_02

Reimers, E. (2017), 'Homonationalism in teacher education - productions of schools as heteronormative national places' in, Journal of Irish Educational Studies, Volume 36, Number 1, March 2017, pp. 91-105. https:// doi.org/10.1080/03323315.2017.1289703

Røthing, A. (2008), 'Homotolerance and heteronormativity in Norwegian classrooms' in, Gender and Education, Volume 20, Number 3, April 2008, pp. 253-266. https://doi.org/10.1080/09540250802000405

Rudoe, N. (2010), 'Lesbian teachers' identity, power and the public/private boundary' in, Sex Education: Sexuality, Society and Learning, Volume 10, Number 1, February 2010, pp. 23-36. https:/ / doi.org/10.1080/14681810903491347

Russell, V., (2010), 'Queer teachers' ethical dilemmas regarding queer youth' in, Journal of Teaching Education, Volume 21, Number 2, May 2010, pp. 143-156. https://doi.org/10.1080/10476211003735427

Sedgeman, J.A. (2005), 'Health Realization/Innate Health: can a quiet mind and a positive feeling state be accessible over the lifespan without stress-relief techniques?' in, International Medical Journal of Experimental and Clinical Research, Volume 11, Number 12, November 2005, pp. 47- 52.

Toussaint, L., Shields, G., Dorn, G., \& Slavich, G. (2016), 'Effects of lifetime stress exposure on mental and physical health in young adulthood: How stress degrades and forgiveness protects health' in, Journal of Health Psychology, Volume 21, Number 6, August 2014, pp. 1004-1014. https://doi.org/10.1177/1359105314544132

Velez, B., Moradi, B., \& Brewster, M. (2013), 'Testing the Tenets of Minority Stress Theory in Workplace Contexts' in, Journal of Counseling Psychology, Volume 60, Number 4, October 2013, pp. 532-542. https://doi.org/10.1037/a0033346

Vicars, M. (2006), 'Who are you calling queer? Sticks and stones can break my bones but names will always hurt me' in, British Educational Research Journal, Volume 32, Number 3, June 2006, pp. 347-361. https:// doi.org/10.1080/01411920600635395

Walls, N. (2008), 'Toward a multidimensional understanding of heterosexism: The changing nature of prejudice' in, Journal of Homosexuality, Volume 55, Number 1, February 2008, pp. 20-70. https:/ / doi.org/10.1080/00918360802129287

Warwick, I., Aggleton, P., \& Douglas, N. (2001), 'Playing it safe: Addressing the emotional and physical health of lesbian and gay pupils in the U.K.' in, Journal of Adolescence, Volume 24, Number 1, February 2001, pp. 129-140. https://doi.org/10.1006/jado.2000.0367

Wright, T., \& Smith, N. (2015), 'A Safer Place? LGBT Educators, School Climate, and Implications for Administrators' in, The Educational Forum, Volume 79, Number 4, September 2015, pp. 394-407. https://doi.org/10.1080/00131725.2015.1068901., Bybee, J., Christiansen, M. H., Croft, W., Ellis, N. C., \& Schoenemann, T. (2009). Language is a complex adaptive system: Position paper. Language Learning, 59, 1-26. doi:10.1111/j.14679922.2009.00533.x

Yosso, T., (2005), 'Whose culture has capital? A critical race theory discussion of community cultural wealth' in, Race, Ethnicity and Education, March 2005, Volume 8, Number 1, pp. 69- 91. https://doi.org/10.1080/1361332052000341006 